\title{
Perspectives towards predictive testing in Huntington disease
}

\author{
S. M. Nagaraja, Sanjeev Jain*, Uday B. Muthane \\ Departments of Neurology and *Psychiatry, National Institute of Mental Health and Neurosciences, Hosur Road, Bangalore - 560 029, \\ India
}

Objective: Genetic counseling for individuals undergoing presymptomatic testing is lacking in India although testing is easily available. This has an impact on family members of Huntington's disease (HD), an autosomal dominant disease, wherein the age at onset of symptoms varies. Aim: We examine if attitudes differ towards presymptomatic testing for HD amongst HD family members, physicians and laypersons. Materials and Methods: A modified questionnaire enquiring about opinions on various personal, family, social and future health care with regards to presymptomatic testing of $\mathrm{HD}$ was designed. A physician explained briefly about HD and presymptomatic testing of $\mathrm{HD}$ and recorded responses of unaffected family members of $\operatorname{HD}(n=25)$ and laypersons $(n=50)$. Medical doctors $(n=50)$ answered the questionnaire based on their knowledge of HD. Results: HD family members, Medical doctors and laypersons were similar in their opinion to undergo the testing. Majority $(60 \%)$ of $\mathrm{HD}$ family members did not wish to communicate test results with their friends when compared to the other two groups. Medical doctors and HD family members were more concerned about certainty of developing disease when the test results are positive. Majority $(80 \%)$ of Medical doctors and less than half in the other groups felt that their decision to have a child would strongly depend on test results. Large proportion (80\%) of HD family members did not wish to report their test results to their employers. Conclusions: Individuals with knowledge about HD and the test differ in their decision of sharing test results and reproductive choices.

Key words: Attitudes, genetic counseling, Huntington's disease, presymptomatic testing

Huntington's disease (HD) is an autosomal dominant progressive neurodegenerative disease, where pre-symptomatic genetic testing is available for over a decade. HD has an unpredictable onset and no treatment for either cure or delaying its progression. Presymptomatic testing is most frequently used in late onset autosomal dominant disorders such as Huntington's disease (HD).Presymptomatic testing is primarily carried out in healthy or asymptomatic individuals to provide information about that individual's future health, with respect to specific inherited diseases. A positive test result may indicate that the individual has a high likelihood of developing the disorder or of excluding it. $^{[1]}$

A positive test for the defective gene has a good accuracy of predicting if an individual is at risk to develop the disease. The unpredictable age at onset in individuals with positive genetic tests for HD poses tremendous concerns. The at-risk population has many questions and fears in their minds about healthcare, psychological and social support from colleagues and their family ${ }^{[2,3]}$ It is thus essential to understand concerns of family members' at-risk for $\mathrm{HD}$ and introspect so that medical personnel, friends and family could address them adequately.

Supportive family bonds and religious values have often guided societal attitudes towards illness. This is particularly true of noncommunicable diseases and is believed to contribute, for example, to the relatively better social outcome of schizophrenia. ${ }^{[4]}$ Modern healtheare is available in India but delivery to patients, especially those with chronic disease, is not uniform. The economic burden of long term care of chronic disease like HD, as in Parkinson's disease, schizophrenia is significant. ${ }^{[5]}$

In the western world where presymptomatic testing is widely available, guidelines for predictive testing for HD have been collaboratively developed by family members and health professionals and is used to advice about predictive testing for HD. ${ }^{[6.7]}$ Approximately 500 individual tests are requested across UK, but these are handled with explicit counseling protocols in place ${ }^{[8]}$ Attitudes to testing vary, e.g., in Italy, where more than half who enlist in the program withdraw from testing, "most frequently due to a more realistic evaluation of all possible consequences of test results, after psychological counseling". ${ }^{[9]}$ In India, clinicians would need to be extremely sensitive while offering these tests due to widely differing educational levels, cultural and 
social beliefs to these issues. We faced many such issues when we began researching into the genetics of HD and in the absence of any formal guidelines decided to evaluate attitudes towards the testing to help us develop guidelines in the future.

We thus conducted this study across a diverse sample to understand the opinions of relatives of $\mathrm{HD}$ probands towards the disease, impact of presymptomatic testing and implications of testing positive. We compared their opinions to those of medical doctors and the lay public who have no direct knowledge of this illness.

\section{Materials and Methods}

\section{Setting}

The study was carried out at the National Institute of Mental Health and Neurosciences, Bangalore, India, a large tertiary referral and research center for psychiatric and neurological disorders.

\section{Subjects}

We compared three groups of individuals, the first group consisted of 25 unaffected family members (spouse, children and first degree family members) of clinically and genetically confirmed HD probands $(n=25)$, the second groups were medical doctors' $(n=50)$ and the third group were laypersons randomly selected as 'controls' $(n=50)$ from within the city of bangalore. A brief written description of HD explaining its genetic nature, clinical features and problems of the disease was given and later explained by a single medical doctor (S.N.) All the participants, who consented to take part in the study were individually administered the modified questionnaire and all clarifications were answered by the research staff during the interview, The questionnaire is in
English and was translated to their language, for ease of explanation, wherever it was required. Subjects were requested to answer questions under the assumption that they were at future risk of developing HD. Individuals with less than 10 years of formal school education were considered uneducated.

\section{Questionnaire}

The instrument contains 30 questions derived from other earlier studies inquiring about personal, family and social issues, as well as future health care. ${ }^{[10-14]}$ The questionnaire were modified with appropriate choices relevant to the socio-cultural situation.

\section{Statistical analysis}

The data was analysed using SPSS version 11 for windows. The mean and standard deviation for age was calculated. The percentage of individual who answered positive was calculated.

\section{Results}

Family members of HD probands were slightly older than the other two groups but were matched for sex and education profile [Table 1]. Similar number of HD family members and doctors (60 and $66 \%$ respectively) would like to undergo genetic testing. A higher number $(78 \%)$ of controls wanted to be tested for HD. Most HD family members $(60 \%)$ did not wish to communicate test results to others. On the contrary, a higher number of doctors and controls wanted to communicate test results to others. HD family members felt that these results were important to their family as compared to controls (34\%). Attitudes towards sharing the results were equivocal. HD family members often did not wish to share knowledge of their genetic status $(60 \%)$ while similar

\begin{tabular}{lcccc}
\hline & Table 1: Age, marital and educational status of participants & \\
\hline Subjects (N) & Age (yrs) mean (SD) & M/F & Married/single & Education $>$ 10 yrs \\
Huntington's disease relatives (25) & $48 \pm 14$ & $16 / 9$ & $18 / 7(2: 1)$ & $96 \%$ \\
Doctors (50) & $30 \pm 9$ & $38 / 12$ & $18 / 32(1: 1.8)$ & $100 \%$ \\
Controls (50) & $33 \pm 12$ & $24 / 26$ & $21 / 29(1: 1.4)$ & $100 \%$ \\
\hline
\end{tabular}

Table 2: Comparison of opinions in HD family members, medical doctors and laypersons

\begin{tabular}{|c|c|c|c|c|}
\hline Questions & Opinion & HDF (\%) & Doctors (\%) & Laypersons (\%) \\
\hline $\begin{array}{l}\text { Given all this information about the predictive test, would I like to } \\
\text { undergo the test }\end{array}$ & Yes & 60 & 66 & 78 \\
\hline $\begin{array}{l}\text { Should I share this information about the predictive test and its } \\
\text { results with others }\end{array}$ & No & 60 & 40 & 40 \\
\hline The test results are important for & $\begin{array}{l}\text { Family members } \\
\text { and friends }\end{array}$ & 88 & 52 & 34 \\
\hline $\begin{array}{l}\text { How important is certainty of getting the disease in my life, if my test } \\
\text { results are positive }\end{array}$ & Very Important & 64 & 70 & 52 \\
\hline I should discus my risk about the disease with & Spouse & 20 & 46 & 12 \\
\hline Can I talk openly to my partner about my anxiety concerning at risk status? & I can & 64 & 76 & 66 \\
\hline $\begin{array}{l}\text { How would the positive test results influence my decision about having } \\
\text { children since the disease is familial }\end{array}$ & Influences & 44 & 80 & 44 \\
\hline I should report a positive result to my employers & Disagree & 80 & 48 & 20 \\
\hline $\begin{array}{l}\text { Will the test results influence the decisions, which I have to take } \\
\text { in my future life? }\end{array}$ & Influences & 56 & 50 & 28 \\
\hline How will I cope with a positive test results & Manage to cope & 80 & 78 & 88 \\
\hline Will the negative test results help me in becoming a better father/mother? & Yes & 72 & 38 & 54 \\
\hline In your opinion, should this illness be covered by insurance or health care? & Yes & 100 & 88 & 90 \\
\hline
\end{tabular}

HDF $=$ HD Family members 
proportion of doctors and controls wanted to share with friends. Doctors $(70 \%)$ were most concerned about the certainty of becoming ill after test results were known. Less than half of all groups would discuss results with a spouse (controls: $12 \%, \mathrm{HD}$ at-risk: $20 \%$ and doctors: $46 \%$ ), but in contrast, they would not discuss their anxieties about the test with them. A large proportion of the doctors $(80 \%)$ confirmed that the result would affect their decision to have children, while less than half of the other two groups would. Majority of HD at risk $(80 \%)$ were unwilling to inform test results to employers while only $20 \%$ of controls felt so [Table 2]. All family members felt that access to organized care, after testing, was imperative, as did a large proportion of the others.

\section{Discussion}

Our survey highlights considerable ambiguities in attitudes of various groups towards testing. Individuals having a greater knowledge of the disease (family members, doctors) were more circumspect in handling genetic information. Medical personnel were most likely to change reproductive decisions and were concerned about the certainty of getting the disease. This probably reflects their greater understanding of the disease. Family members were obviously anxious about their status and were the only group that had difficulty coping with a positive or negative result. Attitudes towards a positive result were expectedly less enthusiastic, but most felt that a negative result would make them become a better parent. Normal controls frequently wanted to request tests but were least likely to share results with family members and did not anticipate that test results will alter their future decisions. They felt the least need to discuss with their spouse, but did not mind letting their employers know. We feel that these responses were different, as the laypersons, unlike the doctors and family members, had no definite idea about the nature of the disease or of genetic testing. In summary, even the lay public, having more than 10 years of formal education, show poor understanding of the illness or test results due to lack of disease information and its genetic implications.

These observations highlight the ambiguous relationship of individuals to predictive testing. Increased understanding of the scientific and clinical issues did not translate into a greater acceptance of the technology. The social responses were suggestive of a greater desire for privacy and autonomy, while at the same time expressing a need for long term care. These needs were most strongly expressed by those having a first hand knowledge of the disease and least by the laypersons.

Most guidelines ${ }^{[15]}$ suggest psychological support or a psychiatric referral to handle emotional consequences of a positive test. These guidelines also suggest the need for frequent re-contact to provide updates on treatment or other emergent issues. ${ }^{[16]}$ This was also observed in our sample, as most individuals were keen to know availability of preventive measures or newer treatments and methods to prevent passing the illness to their future generation. Implicitly, this requires life-long contact with a care service after an individual is tested positive and has a pre-symptomatic status. Issues of individual autonomy, decision-making and availability and affordability of such services need to be addressed in the Indian context as these tests become available. Several family members in our sample had directly experienced difficulties in obtaining reliable care. Many clinical service providers feel it their moral and ethical obligation to maintain long-term contact with individuals who have been tested. However, the legal status of this, as well as the logistics, is a source of worry. ${ }^{[17]}$

There has been a trend towards direct marketing of genetic tests, but their use in India as with female foeticide following sexdetermination is not encouraging. It is advisable that individuals are protected from 'inappropriate advertising and marketing' of genetic tests of late onset disorders. It is observed that geneticists are less likely to consider testing than non-geneticist physicians. ${ }^{[18]}$ Services for continued care do not exist for the disabled or for chronic non-infective diseases in India. Advances in genomics suggest that these tests may soon be available for common multifactorial diseases like Alzheimer's and Parkinson's disease and psychoses. The knowledge of genetic disease status raises new ethical and moral obligations, in addition to impacting on employment and other social roles. ${ }^{[3]}$ These raise important clinical and ethical issues that have rarely been explored in the south Asian context.

Market forces and the aura of 'genetics' often neglect the warning that applying scientific advances to health care does not automatically benefit. ${ }^{[19]}$ The huge lag between diagnoses and available treatment and the absence of any counseling services, suggest the need to establish counseling services and provisions for long term care.

Our study had some limitations as the questionnaire was modified but was not standardized in our population. The questionnaire was in English and every effort was made to adequately communicate the intent of the questions by verbally translating and explaining these into the language the individuals understood by the same person.

Issues of autonomy need to be addressed not only within the doctor-patient relationship, but also the individual's social network. Legal issues about the right to information and disclosure are essential. Most importantly, long term contact and care is crucial. Our study highlights the urgent need for providing genetic tests as part of a comprehensive health care service rather than for a mere diagnostic use and for developing guidelines and policies for handling the complex issues that will be raised by genetic technologies.

\section{Acknowledgements}

We thank Dr. G. Gururaj, Prof. of Epidemiology and NIMHANS for his valuable comments on the questionnaire. We are grateful to the family members of Huntington Disease patients, our medical colleagues and other members of the public who took time to answer the questionnaire. Support of the ICMR is acknowledged to S.J. 


\section{References}

1. Advisory Committee on Genetic Testing (ACGT). Ref Type: Internet Communication Department of Health: UK; [cited 1999 Mar 4].

2. Almqvist EW, Bloch M, Brinkman R, Craufurd D, Hayden MR. A worldwide assessment of the frequency of suicide, suicide attempts, or psychiatric hospitalization after predictive testing for Huntington disease. Am J Hum Genet 1999;64:1293-304.

3. Lapham EV, Kozma C, Weiss JO. Genetic discrimination: Perspectives of consumers. Science 1996;274:621-4

4. Hopper K, Wanderling J. Revisiting the developed versus developing country distinction in course and outcome in schizophrenia: Results from Isos, the who collaborative followup project. International study of Schizophrenia. Schizophr Bull 2000;26:835-46.

5. Ragothaman M, Govindappa ST, Rattihalli R, Subbakrishna DK, Muthane UB. Direct costs of managing Parkinson's disease in india: Concerns in a developing country. Mov Disord 2006;21:1755-8

6. Guidelines for the molecular geneties predictive test in Huntington's Disease. International Huntington Association (IHA) and the World Federation of Neurology (WFN) Research Group on Huntington's Chorea. Neurology 1994;44:1533-6.

7. International Huntington Association and the World Federation of Neurology Research Group on Huntington's Chorea. Guidelines for the molecular genetics predictive test in Huntington's disease. J Med Genet 1994;31:555-9.

8. Harper PS, Lim C, Craufurd D. Ten Years of presymptomatic testing for Huntington's disease: The Experience of the UK Huntington's Disease Prediction Consortium. J Med Genet 2000;37:567-71.

9. Mandich P, Jacopini G, Di Maria E, Sabbadini G, Abbruzzese G, Chimirri F, et al. Predictive testing for Huntington's disease: Ten years' experience in two Italian centres. Ital J Neurol Sci 1998;19:68-74.
10. Barette J, Marsden CD. Attitudes of families to some aspects of Huntington's chorea. Psychol Med 1979;9:327-36.

11. Teltscher B, Polgar S. Objective knowledge about Huntington's disease and attitudes towards predictive tests of persons at risk. J Med Genet 1981;18:31-9.

12. Went L. Ethical issues policy statement on huntington's disease molecular geneties predictive test. International Huntington Association. World Federation of Neurology. J Med Genet 1990;27:34-8.

13. Babul R, Adam S, Kremer B, Dufrasne S, Wiggins S, Huggins M, et al. Attitudes toward direct predictive testing for the Huntington Disease Gene. Relevance for Other Adult-Onset Disorders. The Canadian collaborative group on predictive Testing for Huntington Disease. JAMA 1993;270:2321-5.

14. Thies U, Bockel B, Bochdalofsky V. Attitudes of neurologists, psychiatrists and psychotherapists towards predictive testing for Huntington's disease in Germany. J Med Genet 1993;30:1023-7.

15. Parker M, Lucassen A. Working towards ethical management of genetic testing. Lancet 2002;360:1685-8.

16. Sharpe NF. The duty to recontact: Benefit and harm. Am J Hum Genet 1999;65:1201-4.

17. Hakimian R. Disclosure of Huntington's disease to family members: The dilemma of known but unknowing parties. Genet Test 2000;4:359-64.

18. Wertz DC, Reilly PR. Laboratory policies and practices for the genetic testing of children: A Survey of the helix network. Am J Hum Genet 1997;61:1163-8.

19. Bird S.J. Genetic testing for neurologic diseases. A rose with thorns. Neurol Clin 1989;7:859-70.

\section{Accepted on $09-10-2006$}

Source of Support: ICMR, Conflict of Interest: None declared.

\section{Author Help: Online Submission of the Manuscripts}

Articles can be submitted online from http://www.journalonweb.com. For online submission articles should be prepared in two files (first page file and article file). Images should be submitted separately.

1) First Page File:

Prepare the title page, covering letter, acknowledgement, etc., using a word processor program. All information which can reveal your identity should be here. Use text/rtf/doc/pdf files. Do not zip the files.

2) Article file:

The main text of the article, beginning from Abstract till References (including tables) should be in this file. Do not include any information (such as acknowledgement, your names in page headers, etc.) in this file. Use text/rtf/doc/pdf files. Do not zip the files. Limit the file size to $400 \mathrm{~kb}$. Do not incorporate images in the file. If file size is large, graphs can be submitted as images separately without incorporating them in the article file to reduce the size of the file.

3) Images:

Submit good quality colour images. Each image should be less than $\mathbf{1 0 0} \mathbf{~ k b}$ in size. Size of the image can be reduced by decreasing the actual height and width of the images (keep up to about 3 inches) or by reducing the quality of image. All image formats (jpeg, tiff, gif, bmp, png, eps, etc.) are acceptable; jpeg is most suitable. The image quality should be good enough to judge the scientific value of the image.

Always retain a good quality, high resolution image for print purpose. This high resolution image should be sent to the editorial office at the time of sending a revised article.

4) Legends:

Legends for the figures/images should be included at the end of the article file. 